\title{
Influence of snow type and temperature on snow viscosity
}

\author{
Louis DELMAS
}

\author{
The University Center in Svalbard (UNIS), Longyearbyen, Svalbard, Norway \\ E-mail: louis.delmas@unis.no
}

\begin{abstract}
Three spontaneous avalanches were observed in Lia, Longyearbyen, Svalbard, each occurring naturally under similar temperature conditions. Automatic measurements of temperature inside the snowpack led to examination of the triggering of avalanches in cold conditions following a rapid drop in temperature. The mechanical properties of ice depend on the slab temperature and I ask: could a rapid temperature change affect the mechanical properties differently considering a slab consisting of (1) rounded grains or (2) faceted grains? Snow is considered as a foam of ice crystals, and triaxial deformation tests are performed at constant strain rate to examine the influence of temperature and grain type on the mechanical properties. Although the snow densities in the two sample sets were almost identical, some differences due to grain type were observed. In particular, the set with faceted grain snow started to flow at higher stresses than the set with rounded grains.
\end{abstract}

\section{INTRODUCTION}

As climate change appears to increase the amount of snow precipitation in the Arctic, some areas of Longyearbyen, Svalbard, are now exposed to a higher avalanche risk (Larsen, 2005) than during the 1970s when the settlements were first established (Hestnes, 2001). This situation has led to a snow stability study in the Arctic aimed at improving avalanche-warning capabilities. Despite the fact that the slopes surrounding Longyearbyen are at low altitude (150$500 \mathrm{~m}$ a.s.l.), the snow lying on these slopes can be compared with high-altitude alpine snowpacks at lower latitudes. With no high vegetation, Svalbard snow is very much exposed to redistribution by the wind, and almost all the snow that is deposited is transported long distances. This leads to the formation of cornices, wind drifts and windpacked slabs.

In the study area considered here, Lia in Longyearbyen, three naturally triggered avalanches were observed (23 November 2007, 29 November 2008 and 5 December 2010). These avalanches released under similar meteorological conditions: during the polar night, no wind and a temperature drop $\left(10^{\circ} \mathrm{C}\right.$ in a $\sim 6$ hour period) followed by a rapid temperature increase. In particular, on 29 November 2008, the temperature changes had two effects. First, owing to the high temperature gradients $\left(30-35^{\circ} \mathrm{C} \mathrm{m}^{-1}\right)$, a weak layer formed within the snowpack $\sim 40 \mathrm{~cm}$ below the surface, consisting of small (1-2 mm) depth-hoar crystals. This was measured by observation of the crown layering and a snow profile on a nearby snow pit. Second, the temperature increase caused a warming of the slab that changed the snow viscosity, so a greater proportion of the deformation was transmitted to the weak layer.

As stated above, the Svalbard snowpack is very much influenced by the wind. Transport by wind has the effect of reducing the grain size because of sublimation in the air and destruction of the grain structure, Furthermore, the wind has been found to reduce the grain specific surface area (SSA) (Cabanes and others, 2003). The grains settle as windpacked snow, which is much denser than loose fresh snow. From previous experience this leads to two types of slab microstructure. The first is of rounded grains due to a nearzero temperature gradient and consists of small ice spheres bonded together (Kaempfer and Schneebeli, 2007). The second is of faceted grains due to low temperature gradients (Colbeck, 1982) and consists of 'crystal-like' grains bounded by very thin and angular bonds. However, the macro-density can be the same for the two types, indicating that a correct microstructure description is essential to predict the viscous material behaviour.

The behaviour of snow under load depends very much on how rapidly it is loaded. For fast loading, i.e. for high strain rates $\left(>10^{-3} \mathrm{~s}^{-1}\right)$, snow is brittle. For low strain rates $\left(<10^{-5} \mathrm{~s}^{-1}\right)$, snow is ductile and is considered a viscoelastic material. A transition from brittle to ductile behaviour is found at a strain rate of $\sim 10^{-4} \mathrm{~s}^{-1}$, depending on temperature and microstructure (Kirchner and others, 2001).

Human-triggered slab avalanches are often initiated by loosening the slab shear support along a weak layer. The corresponding timescale is short enough to allow consideration of snow as a quasi-brittle medium (Schweizer and others, 2008). As soon as the brittle fracture is initiated, the failure process becomes dynamic, as a crack propagates parallel to the slope within the weak layer and perpendicular to the slope inside the slab (Heierli and Zaiser, 2008). In this case, viscoelastic and thermal aspects of snow deformation are generally neglected. Their effect on the mechanics of snow slab fracture is considered not very strong since the snow slab is rapidly unloading as it releases its strain energy during failure (Bažant and others, 2003).

For naturally triggered avalanches, the initiation takes longer. Regardless of the natural triggering sources, snow accumulation, wind loading or temperature change, the timescale involved in the snow-cover evolution is much greater. The viscous behaviour of the slab and the weak layer then becomes predominant over their quasi-brittle properties (Louchet, 2001). Gubler and Bader (1989) found that ductile failure is a necessary condition for the initiation of brittle fracture propagation in the case of naturally triggered avalanches. Both the slab and the weak-layer viscosities must be considered. In the weak layer, stresses, strain rates and strains will be locally concentrated, resulting in inhomogeneities, and this will be the location of the transition from ductile to brittle behaviour. But the slab viscosity must not be omitted. This is the medium through which all the stresses, strains and strain rates will be transmitted to the weak layer. To consider the slab as purely 
elastic would eliminate the possibility of a delayed application of the stresses. Heierli and Zaiser (2008) have presented an analytical model of the mix between slope-parallel slip and slope-normal deformation during the failure of a weak layer. Although their model is based on linear elastic fracture mechanics and thus does not take into account the longterm deformation of the snow, it shows the importance of the flexural rigidity of the slab in regard to crack propagation inside the weak layer. Variation of the viscosity of the slab will strongly affect its flexural rigidity and thus the amount of stress, strain, and strain rate transmitted to the weak layer. A large slab flexural rigidity will allow the weak layer to remain fragile as the forces build up on top of the slab. In the case of a temperature increase leading to a viscosity decrease, the forces applied to the slab will be progressively transmitted to the weak layer as the slab changes its flexural rigidity, leading to the possibility of a catastrophic increase of strain rate inside the weak layer and thus the initiation of a quasi-brittle failure. A better knowledge of the viscous properties of snow, especially its microstructure and thermal properties, is then necessary in order to understand the initiation of natural slab avalanches.

The aim of this paper is to quantify the temperature and microstructure dependence on the viscous behaviour of snow. A power law will be used to describe the relationship between strain rate and yield stress, $\sigma_{y}$ defined as the stress at which a steady-state viscous deformation is reached.

In order to measure the viscous behaviour, triaxial tests are performed. Triaxial tests have been performed in the past by Salm (1967) in order to formulate a failure criterion for snow based on conserved energy levels at fracture. Navarre and others (1987) showed the visco-elasto-plastic behaviour of snow and its capacity to strain-harden. Bartelt and von Moos (2000), Scapozza and Bartelt (2003a,b) and von Moos and others (2003) described the snow as a viscoelastic material. The relationship between snow yield stress and strain rate is a power law similar to that for polycrystalline ice.

\section{METHODS}

\section{Sampling and testing method}

Samples were collected from a natural snowpack on a slope called 'Lia' overhanging Longyearbyen $\left(78^{\circ} 21^{\prime} 64^{\prime \prime} \mathrm{N}\right.$, $\left.15^{\circ} 65^{\prime} 43^{\prime \prime} \mathrm{E}\right)$. During sampling for snow with rounded grains the in situ temperature was $-17^{\circ} \mathrm{C}$. During sampling for snow with faceted grains the temperature was $-22^{\circ} \mathrm{C}$. Samples were cored using a $60 \mathrm{~mm}$ diameter aluminium tube. They were placed in a shell, avoiding compression or disturbance, and transported in an isotherm box. In order to avoid changes in the microstructure due to sublimation in the cold laboratory, the samples were placed in air-proof bags to avoid exchanges of water vapour with the environment. Microstructure type and density were recorded just before the tests to take into account possible changes that could have occurred before the test was performed. No major change of grain type or density was observed.

Samples were tested in a cold laboratory at the University Center in Svalbard within 6 hours of sampling, using the compression apparatus 'KNEKKIS' into which a custommade triaxial cell was placed. KNEKKIS is a deformationcontrolled compression machine that was designed to make uniaxial compression tests at constant strain rate. The machine was developed at the Norwegian University of Science and Technology in Trondheim. The lower cylinder

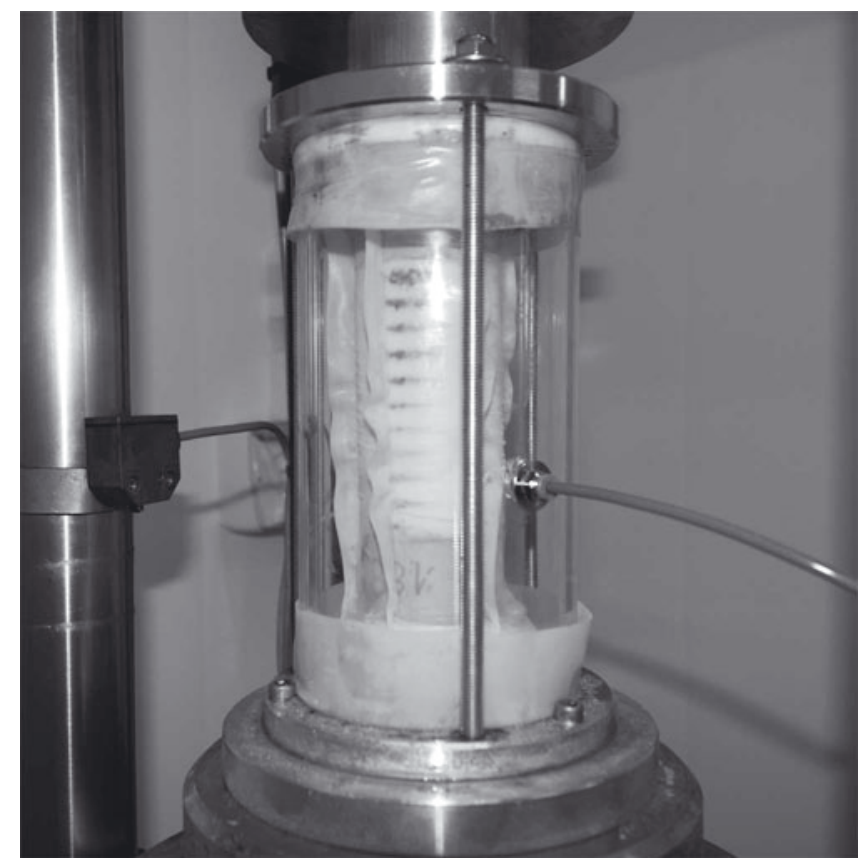

Fig. 1. The triaxial cell.

of the compression machine moves upwards with a userselected constant velocity ranging from 0.001 to $1.5 \mathrm{~mm} \mathrm{~s}^{-1}$. The maximum load that can be achieved is $100 \mathrm{kN}$. During the tests, the load and deformation values are plotted in real time on a display and stored to a file at operator-selected strain intervals. The maximum sampling rate that can be achieved is $5000 \mathrm{~Hz}$. In order to perform triaxial tests, a custom-made triaxial cell was used. This set-up allows us to apply a confining pressure and to measure the snow resistance in compression for a given strain rate.

The triaxial cell utilizes compressed air rather than a liquid to apply the confining pressure. A liquid produces a hydrostatic pressure, which has a gradient from the top to the bottom of the sample. For snow this is not acceptable. During the test, the volume of the chamber where the air is compressed decreases due to the compression of the samples. In order to maintain a constant pressure inside the chamber, an adjustable release valve was used in series with the air-pressure calibration pump. A rubber tube membrane was used to apply the confining pressure. The setting of the membrane is always delicate even for soil (for which the apparatus was originally designed); the sample must not be deteriorated by the placement of the membrane. Since snow is an even more delicate material than soil, an alternative approach was taken for the application of the confining pressure through the membrane. The rubber tube diameter was chosen to be much larger than the sample diameter. The rubber tube was folded around a transparent plastic tube (Fig. 1), and the air pressure was applied between the plastic tube and the rubber tube. This allowed the confining pressure to be applied around the sample before the beginning of the test, without deteriorating it.

The confining pressure was set to $20 \mathrm{kPa}$. As described by Bartelt and von Moos (2000), the axial yield stress does not depend on the applied confining pressure. However, it was observed that applying a confining pressure at the beginning of the test was useful to have the same pre-consolidation for all the samples, thus eliminating any differences in preconsolidation due to transport and manipulation. To set up 


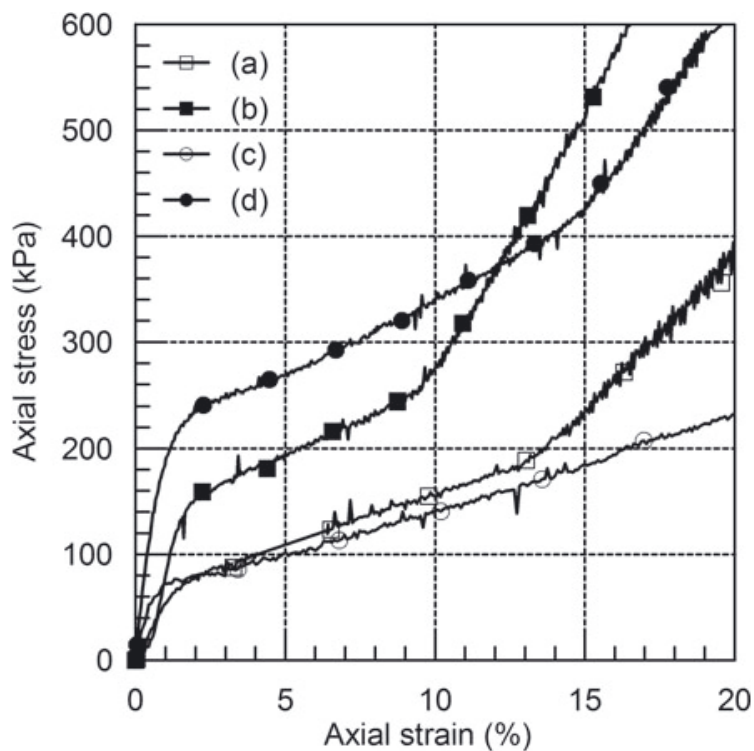

Fig. 2. Stress-strain behaviour for rounded grain snow: (a) $T=-5^{\circ} \mathrm{C}$, strain rate $=4 \times 10^{-5} \mathrm{~s}^{-1}$; (b) $T=-5^{\circ} \mathrm{C}$, strain rate $=4 \times 10^{-4} \mathrm{~s}^{-1}$; (c) $T=-15^{\circ} \mathrm{C}$, strain rate $=4 \times 10^{-5} \mathrm{~s}^{-1}$; (d) $T=-15^{\circ} \mathrm{C}$, strain rate $=$ $4 \times 10^{-4} \mathrm{~s}^{-1}$.

the pre-consolidation, the confining pressure of $20 \mathrm{kPa}$ was applied 1 hour before the start of the test.

The samples were tested at two temperatures $\left(-5^{\circ} \mathrm{C}\right.$ and $\left.-15^{\circ} \mathrm{C}\right)$ and two strain rates $\left(4 \times 10^{-5} \mathrm{~s}^{-1}\right.$ and $\left.4 \times 10^{-4} \mathrm{~s}^{-1}\right)$. These temperature values were chosen because they cover the range of temperatures encountered in Svalbard. The strain-rate values were chosen to surround the brittle-toductile transition in snow and ice, which occurs at a strain rate of $\sim 10^{-4} \mathrm{~s}^{-1}$. All tests were performed twice for reproducibility purposes.

Two microstructure types were tested: (1) rounded grains (well rounded, $0.2-0.3 \mathrm{~mm}$ grain size, average density $367 \mathrm{~kg} \mathrm{~m}^{-3}$ ); and (2) faceted grains (wind-accumulated snow, $0.2-0.3 \mathrm{~mm}$ grain size, 1 week old and subjected to small temperature gradient, average density $370 \mathrm{~kg} \mathrm{~m}^{-3}$ ). Grain size was measured using a handheld microscope with $25 \times$ magnification.

\section{RESULTS}

Figures 2 and 3 show stress-strain curves obtained after testing in the triaxial cell for the rounded grain snow and the faceted snow, respectively. Three stages can be distinguished from the curves: first an elastic stage, then hardening and finally densification. These three stages confirm the assessment of snow as a foam of ice (Gibson and Ashby, 1997). The yield stress $\sigma_{y}$ corresponds to the first inflexion point of the curves. Its value is estimated by fitting straight lines to the elastic and hardening stages of the curves, then calculating the coordinates of the intersection point.

The hardening modulus, estimated from the slopes of the curves during the second stage, seems unaffected by temperature or strain rate for rounded grain snow. The average values for the hardening modulus in rounded grain snow are $13.4 \pm 2.3 \mathrm{kPa}$ at $-5^{\circ} \mathrm{C}$ and $13.3 \pm 5.1 \mathrm{kPa}$ at $-15^{\circ} \mathrm{C}$.

On the other hand a significant dependence of hardening modulus on temperature was found for faceted grain snow. The average values for the hardening modulus for faceted

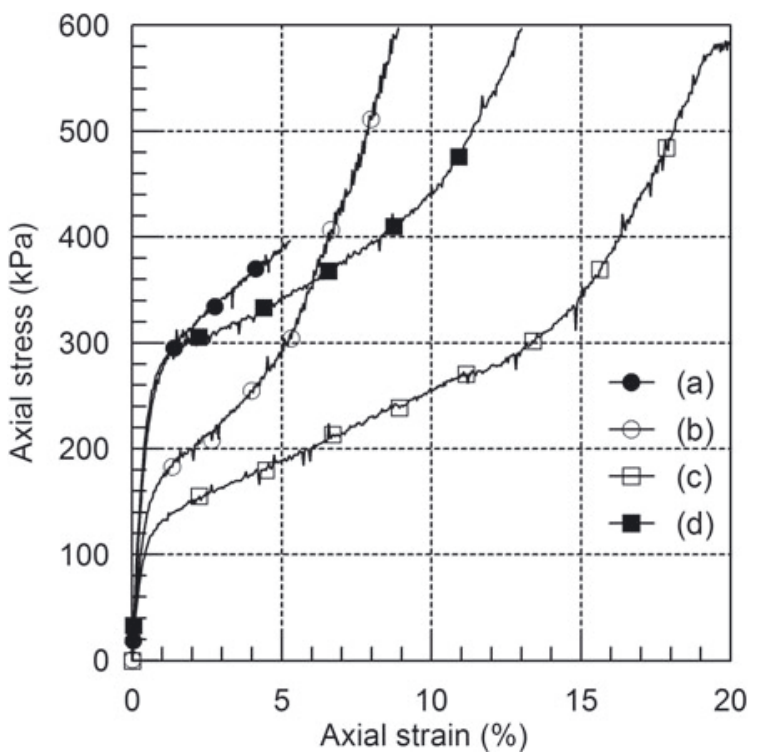

Fig. 3. Stress-strain behaviour for faceted grain snow: (a) $T=-15^{\circ} \mathrm{C}$, strain rate $=4 \times 10^{-4} \mathrm{~s}^{-1}$; (b) $T=-15^{\circ} \mathrm{C}$, strain rate $=4 \times 10^{-5} \mathrm{~s}^{-1}$; (c) $T=-5^{\circ} \mathrm{C}$, strain rate $=4 \times 10^{-5} \mathrm{~s}^{-1}$; (d) $T=-5^{\circ} \mathrm{C}$, strain rate $=$ $4 \times 10^{-4} \mathrm{~s}^{-1}$. Not all samples were tested through to the densification stage, as the primary interest of this study is the yield stress and the hardening modulus. Therefore, curve (a) stops at a strain of 5\%.

grain snow are $13.6 \pm 2.0 \mathrm{kPa}$ at $-5^{\circ} \mathrm{C}$ and $23.7 \pm 4.0 \mathrm{kPa}$ at $-15^{\circ} \mathrm{C}$.

The yield stress has been found to increase with increasing strain rate and to decrease with increasing temperature. The relationship between yield stress, strain rate and temperature can be expressed as a power law based on the Arrhenius relation:

$$
\dot{\varepsilon}=A_{0} \mathrm{e}^{\frac{Q}{R T}}\left(\sigma_{y}\right)^{n}=A\left(\sigma_{y}\right)^{n}
$$

where $\dot{\varepsilon}$ is the applied strain rate $\left(\mathrm{s}^{-1}\right), A_{0}$ is a densitydependent material parameter $\left(\mathrm{kPa}^{-\mathrm{n}} \mathrm{s}^{-1}\right), Q$ is the activation energy $\left(\mathrm{kJ} \mathrm{mol}^{-1}\right), R$ is the gas constant $\left(\mathrm{kJ} \mathrm{mol}^{-1} \mathrm{~K}^{-1}\right), T$ is the temperature $(\mathrm{K}), \sigma_{y}$ is the yield stress $(\mathrm{kPa})$ and $n$ is a dimensionless exponent.

Figure 4 shows the relationships between the applied strain rate and the yield stress in a log-log plot for rounded grain snow at the two temperatures. Figure 5 shows the same for faceted grain snow. Assuming a power law of the form of Eqn (1), a straight line (log-log plot) is plotted between the two pairs of data points for each dataset. It has been shown by Narita (1980, 1983), Kirchner and others (2001) and Scapozza and Bartelt (2003a,b) that the best fit obtained with more than two sets of points is linear on a log-log plot. Data obtained by Scapozza and Bartelt $(2003 a, b)$ for the temperature range $-11.2^{\circ} \mathrm{C}$ to $-18.7^{\circ} \mathrm{C}$ for rounded grain snow with density $355 \mathrm{~kg} \mathrm{~m}^{-3}$ indicate an exponent $n \approx 3.7$. In this study, at $-15^{\circ} \mathrm{C}$ with density $367 \mathrm{~kg} \mathrm{~m}^{-3}, n \approx 3.2$. For a temperature of $-4.6^{\circ} \mathrm{C}$ for rounded grain snow with density $355 \mathrm{~kg} \mathrm{~m}^{-3}$, Scapozza and Bartelt (2003a) found $n \approx 2.7$. In this study, at $-5^{\circ} \mathrm{C}$ with a density of $367 \mathrm{~kg} \mathrm{~m}^{-3}, n \approx 2.8$.

For the value of $A$ in Eqn (1), for rounded grain snow with density $370 \mathrm{~kg} \mathrm{~m}^{-3}$ at $-12^{\circ} \mathrm{C}$, Scapozza and Bartelt (2003a,b) found $A \approx 10^{-23} \mathrm{~Pa}^{-n} \mathrm{~s}^{-1}$. In this study, for a density of $367 \mathrm{~kg} \mathrm{~m}^{-3}$ and the same type of snow at $-15^{\circ} \mathrm{C}$, $A \approx 6.67 \times 10^{-24} \mathrm{~Pa}^{-3.3} \mathrm{~s}^{-1}$. Taking into account the slight differences in density, temperature and strain rate between 


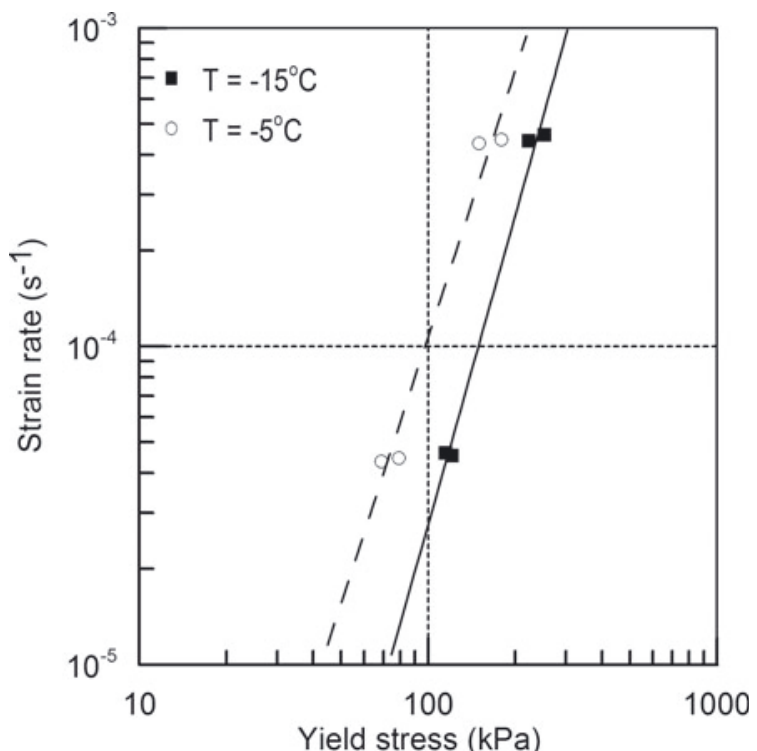

Fig. 4. Strain rate versus yield stress for rounded grain snow at $-5^{\circ} \mathrm{C}$ and $-15^{\circ} \mathrm{C}$. At $-5^{\circ} \mathrm{C}$ the best fit to the data gives $n=2.8$ and $A=1.2 \times 10^{-18} \mathrm{~Pa}^{-2.8} \mathrm{~s}^{-1}$. At $-15^{\circ} \mathrm{C}$ the best fit for the data gives $n=3.2$ and $A=6.67 \times 10^{-24} \mathrm{~Pa}^{-3.2} \mathrm{~s}^{-1}$.

the two datasets, the values of both $n$ and $A$ are in agreement with those published by Scapozza and Bartelt $(2003 \mathrm{a}, \mathrm{b})$.

At both $-15^{\circ} \mathrm{C}$ and $-5^{\circ} \mathrm{C}$ the yield stress is lower for rounded grain snow than for faceted grain snow, i.e. faceted snow starts to flow in steady state and at higher stress than snow with round grains. The difference between the two types of snow is greater at higher temperature.

The deformation activation energy $Q$ can be estimated using Eqn (1) at the two test temperatures used here, $T_{1}$ and $T_{2}$ :

$$
Q=\frac{R\left(n_{1} \ln \sigma_{y 1}-n_{2} \ln \sigma_{y 2}\right)}{\frac{1}{T_{1}}-\frac{1}{T_{2}}}
$$

where $Q$ is the activation energy $\left(\mathrm{kJ} \mathrm{mol}^{-1}\right), R$ is the gas constant $\left(\mathrm{kJ} \mathrm{mol}^{-1} \mathrm{~K}^{-1}\right), T_{1}$ and $T_{2}$ are the temperatures $(\mathrm{K}), n_{1}$ and $n_{2}$ are the calculated dimensionless exponents and $\sigma_{y 1}$ and $\sigma_{y 2}$ are the measured yield stresses (Pa). Using Eqn (2) and the values established from Figure 4, the activation energy for the rounded grain snow, $Q_{R}$, over the temperature range $-15^{\circ} \mathrm{C}<T<-5^{\circ} \mathrm{C}$ is as follows: $Q_{R}=344 \mathrm{~kJ} \mathrm{~mol}^{-1}$ at the strain rate of $4 \times 10^{-5} \mathrm{~s}^{-1}$ and $Q_{\mathrm{R}}=337 \mathrm{~kJ} \mathrm{~mol}^{-1}$ at the strain rate of $4 \times 10^{-4} \mathrm{~s}^{-1}$. Using the values established from Figure 5, the activation energy for faceted snow, $Q_{F}$, is as follows: $Q_{\mathrm{F}}=605 \mathrm{~kJ} \mathrm{~mol}^{-1}$ at the strain rate of $4 \times 10^{-5} \mathrm{~s}^{-1}$ and $Q_{\mathrm{F}}=600 \mathrm{~kJ} \mathrm{~mol}^{-1}$ at the strain rate of $4 \times 10^{-4} \mathrm{~s}^{-1}$. That is, the activation energy for faceted grain snow is twice that for rounded grain snow. For rounded grain snow with density $355 \mathrm{~kg} \mathrm{~m}^{-3}$ and strain rate $4.4 \times 10^{-5} \mathrm{~s}^{-1}$, Scapozza and Bartelt $(2003 \mathrm{a}, \mathrm{b})$ found $Q_{\mathrm{R}}=413 \mathrm{~kJ} \mathrm{~mol}^{-1}$. They found that values of $Q_{\mathrm{R}}$ decrease with increasing density to $120 \mathrm{~kJ} \mathrm{~mol}^{-1}$ at density $440 \mathrm{~kg} \mathrm{~m}^{-3}$, and linear interpolation between these values gives a value of $Q=366 \mathrm{~kJ} \mathrm{~mol}^{-1}$ at density $367 \mathrm{~kg} \mathrm{~m}^{-3}$, within $6 \%$ of the value for $Q_{\mathrm{R}}$ from this study.

\section{DISCUSSION}

Microstructure was observed to influence the yield stress level. The two types of snow tested were dry rounded grain snow and wind-packed faceted snow. Both had

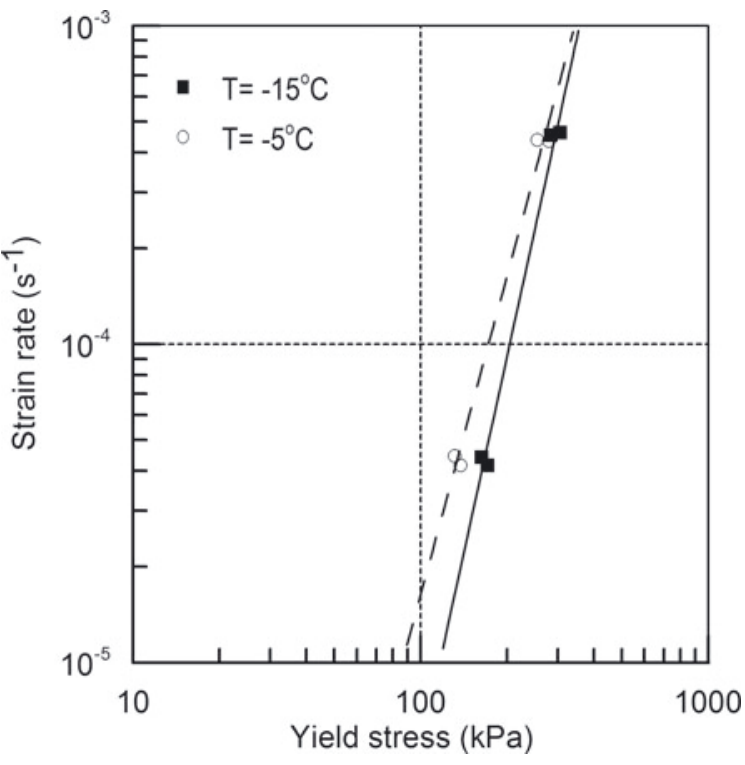

Fig. 5. Strain rate versus yield stress for faceted snow at $-5^{\circ} \mathrm{C}$ and $-15^{\circ} \mathrm{C}$. At $-5^{\circ} \mathrm{C}$ the best fit to the data gives $n=3.3$ and $A=4.3 \times 10^{-22} \mathrm{~Pa}^{-3.3} \mathrm{~s}^{-1}$. At $-15^{\circ} \mathrm{C}$ the best fit for the data gives $n=4.1$ and $A=1.5 \times 10^{-26} \mathrm{~Pa}^{-4.1} \mathrm{~s}^{-1}$.

approximately the same density and the same grain size. For the rounded grain snow a lower yield stress was observed, i.e. this snow starts to flow in steady state at a lower applied stress than the faceted grain snow. This has been verified by a discrete-element two-dimensional biaxial shear simulation in which rounded grain material reached steady-state flow at lower axial strains (Mirghasemi and others, 2002). An increase was also observed in the hardening modulus with decreasing temperature in faceted snow. Thus, at $-15^{\circ} \mathrm{C}$, the faceted snow starts to flow at a higher applied stress and the viscosity is higher than for rounded grain snow. The particle shape has an influence on the internal friction of snow. A comparison with a granular material such as sand is tempting; even though snow is a bonded material, internal friction has an increasing influence on the mechanical properties as the strain increases.

Figure 6 shows low-temperature scanning electron microscope (LT-SEM) pictures of two types of snow. Figure 6a shows rounded grains and Figure $6 \mathrm{~b}$ shows wind-packed snow. These pictures are unfortunately not taken from one of the samples tested in this study, but are presented here as an illustration. Even though the grain size is not the same in both types in Figure 6, it is possible to get an idea of the differences in particle-size distribution (PSD). The wind-packed snow PSD seems wider than the rounded grain snow PSD, composed of a range of grain sizes, from very small to large. The rounded grain snow in this study has a much narrower grain-size distribution, with quite 'homogeneous' particle size. The difference in microstructure may cause increased friction in the case of wind-packed snow despite the faceted character. Indeed a wider grain-size distribution increases the number of contacts between the grains, and thus the friction. In this study the wind-packed snow was 1 week old (since it last deposited after wind transport) and was slightly faceted.

It can be hypothesized that: (1) the packing process has a greater effect on the stress than the bonding process; and (2) the shape of the grains and their size distribution has some influence on the resisting forces within the snow. A comparison can be made with gouge behaviour. Tests have 


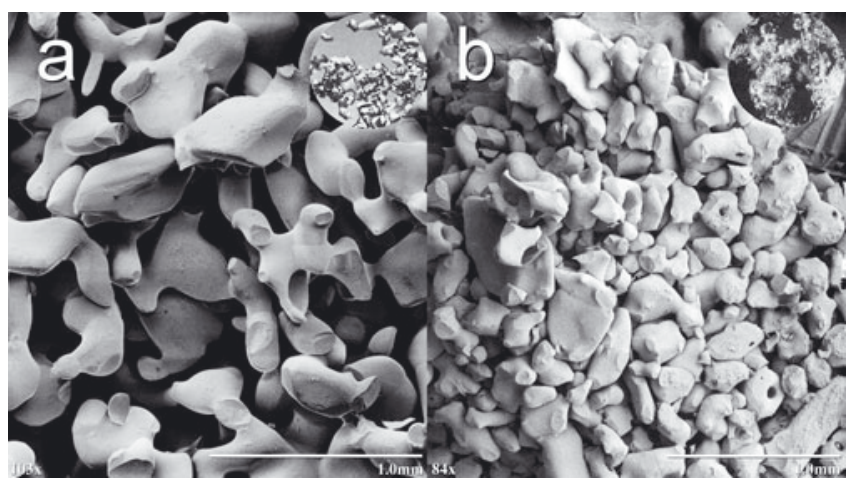

Fig. 6. Two types of microstructure: (a) rounded grains and (b) windpacked snow. From Electron and Confocal Microscopy Laboratory, Agricultural Research Service, US Department of Agriculture.

been reported comparing the friction of three kinds of material (Mair and others, 2002; Anthony and Marone, 2005): (1) spherical particles and a narrow PSD; (2) angular particles and a narrow PSD; and (3) spherical particles with a wide PSD. It appears that in every case the friction stresses within type (2) were higher than within type (1).

Figure 7 shows the possible behaviour of load-bearing chains in a gouge, which can be compared with those existing in snow except that there is no cohesion due to bonding in gouges. Figure 7 exhibits the behaviour of the chains in shear; this is comparable with triaxial testing as a shear plain develops in the triaxial samples at $45^{\circ}$ to the maximum stress axis.

It seems that the friction angle is higher in an angular material than in a spherical material. The contact stresses, however, are higher for a chain made of spherical grains. The widening of the PSD also increases the friction angle of the material. Despite the relatively low number of bonds in faceted snow, the grain shape and PSD have a large effect on the material resistance. It is now known that rounded grain snow is not composed simply of spheres and concave bonds but, since ice is a crystalline material, the bond must have a grain boundary groove (Colbeck, 1998). Thus the contact feature between two particles of a gouge is not so far from that observed in rounded grain snow.

Two other mechanisms, besides friction, occur at the microscale. Intercrystalline deformation or grain boundary sliding corresponds to the deformation and rearrangement of grains relative to each other; this is highly dependent on porosity. Intracrystalline deformation or basal slip corresponds to creep of monocrystals of ice. Recent studies question the relative influence of those two mechanisms, favouring intracrystalline deformation mechanisms (Meysonnier and others, 2009; Theile and others, 2011). The shear stresses on a single crystal basal plane can vary by five orders of magnitude depending on the plane orientation relative to the stress orientation (Schulson and Duval, 2009). This may explain the difference in yield stress if the polycrystalline anisotropy of faceted grains and rounded grains were found to be different. Unfortunately crystallography of the snow grains is beyond the scope of this study.

The large difference in activation energy found between rounded grain snow and faceted grain snow indicates a difference in the underlying deformation mechanisms. There may be several explanations. First, the internal friction, as stated earlier, will play a role in increasing the energetic
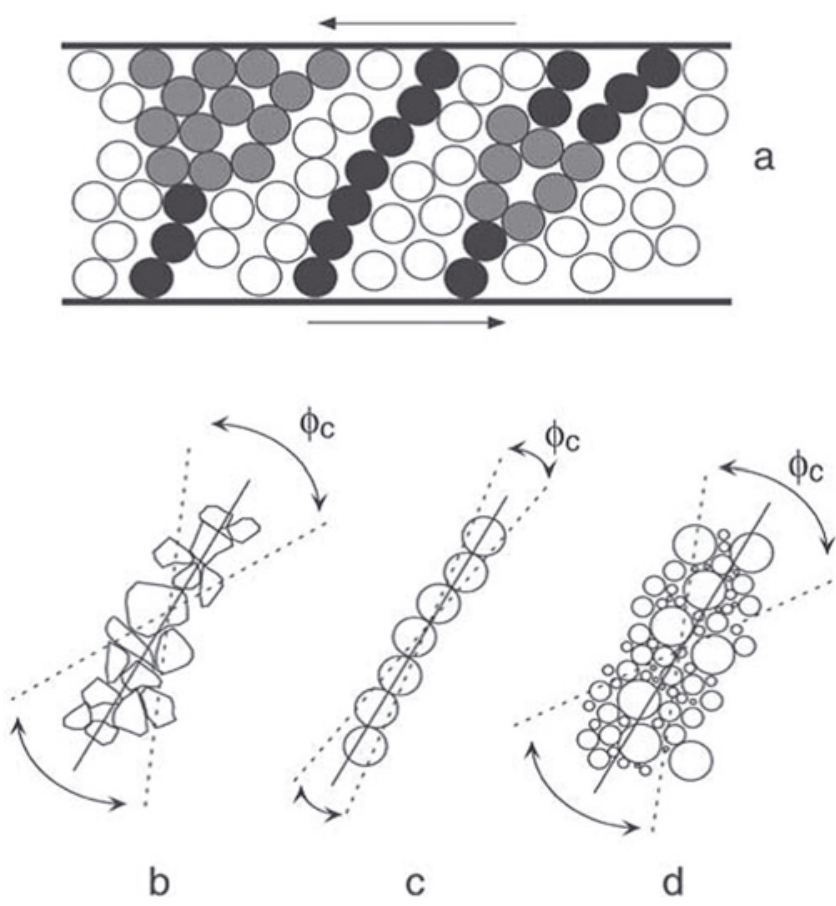

Fig. 7. (a) Illustration of possible force chain geometries for a granular layer under shear. Dark grey circles indicate particles bearing high load, light grey circles indicate particles bearing moderate loads, and white circles indicate 'spectator' particles not bearing appreciable load. Note that stress can be supported by sets of localized chains of highly stressed particles (middle) or by diffuse webs of particles under lower stress (left, right). Examples of stress chains are shown for (b) angular gouge, (c) narrow PSD spherical particles and (d) wide PSD spherical particles. Solid line indicates optimal chain orientation, and dotted lines demark range of possible stable orientations. $\Phi_{\mathrm{c}}$ defines a critical angle for stress chains; outside this range, stress chains fail by inter-particle slip or rolling (Mair and others, 2002).

barrier in the case of faceted grains. Second, angular grain shapes and a large PSD in faceted snow may cause more bonding. The angular shapes are ephemeral within the snow, and, as they sublimate, water vapour is released and is available for recrystallization (Colbeck, 1982). On the other hand, rounded grain snow with smoother surfaces may not be able to sublimate enough to get the necessary supersaturation to facilitate rapid bonding.

\section{CONCLUSIONS}

Triaxial tests were performed on snow at two temperatures for two types of microstructure. It appears that snow that went through isothermal metamorphism for some time, composed of rounded grains, will begin to flow at lower stresses than faceted wind-packed snow, even though it has gone through a small temperature gradient. This may be partly due to the friction angle between the grains, which is higher for the angular faceted grains. Between $-5^{\circ} \mathrm{C}$ and $-15^{\circ} \mathrm{C}$ the activation energy for faceted grains was found to be twice that for rounded grain snow. This shows a clear difference in the underlying mechanisms appropriate to each type of snow. With regard to slab stability considerations, these results show that a faceted wind-packed slab will deform less under viscous behaviour than a rounded grain slab. This implies that the faceted slab will accumulate more stress, while the rounded grain slab will tend to flow 
more, gradually releasing its stress to the underlying snow. In contrast, the faceted slab will start releasing its stress at higher values, subjecting the underlying weak layer to higher stress ranges. A catastrophic crack propagation would then be promoted even more by a faceted slab.

\section{ACKNOWLEDGEMENTS}

I thank The University Center in Svalbard (UNIS) for funding the study, and Adrien Galinier for assistance in performing the deformation experiments.

\section{REFERENCES}

Anthony JL and Marone C (2005) Influence of particle characteristics on granular friction. J. Geophys. Res., 110(B8), B08409 (doi: 10.1029/2004JB003399)

Bartelt P and von Moos M (2000) Triaxial tests to determine a microstructure-based snow viscosity law. Ann. Glaciol., 31, 457-462 (doi: 10.3189/172756400781819761)

Bažant ZP, Zi G and McClung D (2003) Size effect law and fracture mechanics of the triggering of dry snow slab avalanches. J. Geophys. Res., 108(B2), 2119 (doi: 10.1029/2002JB001884)

Cabanes A, Legagneux L and Domine F (2003) Rate of evolution of the specific surface area of surface snow layers. Environ. Sci. Technol., 37(4), 661-666

Colbeck SC (1982) Growth of faceted crystals in a snow cover. CRREL Rep. 82-29

Colbeck SC (1998) Sintering in a dry snow cover. J. Appl. Phys., 84(8), 4585-4589 (doi: 10.1063/1.368684)

Gibson LJ and Ashby MF (1997) Cellular solids: structure and properties. Cambridge University Press, Cambridge

Gubler H and Bader HP (1989) A model of initial failure in slabavalanche release. Ann. Glaciol., 13, 90-95

Heierli J and Zaiser M (2008) Failure initiation in snow stratifications containing weak layers: nucleation of whumpfs and slab avalanches. Cold Reg. Sci. Technol., 52(3), 385-400 (doi: 10.1016/j.coldregions.2007.02.007)

Hestnes E (2001) Vannledningsdalen-Gruvedalen, Longyearbyen Skredfarevurdering. NGI Report 20011167-1. Norges Geotekniske Institutt, Oslo

Kaempfer TU and Schneebeli M (2007) Observation of isothermal metamorphism of new snow and interpretation as a sintering process. J. Geophys. Res., 112(D24), D24101 (doi: 10.1029/ 2007JD009047)

Kirchner HOK, Michot G, Narita H and Suzuki T (2001) Snow as a foam of ice: plasticity, fracture and the brittle-to-ductile transition. Philos. Mag. A, 81(9), 2161-2181 (doi: 10.1080/ 01418610108217141)
Larsen JO (2005) The influence of climate change on natural hazards in Arctic region. In Senneset K, Flaate K and Larsen JO eds. Landslides and Avalanches: Proceedings of the 11th International Conference and Field Trip on Landslides, 1-10 September 2005, Norway. Taylor and Francis, London, 229-232

Louchet F (2001) Creep instability of the weak layer and natural slab avalanche triggerings. Cold Reg. Sci. Technol., 33(2-3), 141-146 (doi: 10.1016/S0165-232X(01)00035-0)

Mair K, Frye KM and Marone C (2002) Influence of grain characteristics on the friction of granular shear zones. J. Geophys. Res., 107(B10), 2219 (doi: 10.1029/2001JB000516)

Meyssonnier J, Philip A, Capolo L and Mansuy P (2009) Experimental studies of the viscoplasticity of ice and snow. In Kolymbas D and Viggiani G eds. Mechanics of natural solids. Springer, Berlin, 203-221

Mirghasemi AA, Rothenburg L and Matyas EL (2002) Influence of particle shape on engineering properties of assemblies of twodimensional polygon-shaped particles. Géotechnique, 52(3), 209-217

Narita H (1980) Mechanical behaviour and structure of snow under uniaxial tensile stress. J. Glaciol., 26(94), 275-282

Narita H (1983) An experimental study on tensile fracture of snow. Contrib. Inst. Low Temp. Sci., Ser. A 32, 1-37

Navarre JP, Taillefer A, Flavigny E, Desrues J and Gauthier T (1987) Mécanique de la neige. Essais en laboratoire sur la résistance de la neige. IAHS Publ. 162 (Symposium at Davos 1986 Avalanche Formation, Movement and Effects), 129-137

Salm B (1967) An attempt to clarify triaxial creep mechanics of snow. In Ôra $\mathrm{H}$ ed. Physics of snow and ice. Institute of Low Temperature Science, Hokkaido University, Sapporo, 857-874

Scapozza C and Bartelt P (2003a) The influence of temperature on the small-strain viscous deformation mechanics of snow: a comparison with polycrystalline ice. Ann. Glaciol., 37, 90-96 (doi: 10.3189/172756403781815410)

Scapozza C and Bartelt P (2003b) Triaxial tests on snow at low strain rate. Part II. Constitutive behaviour. J. Glaciol., 49(164), 91-101 (doi: 10.3189/172756503781830890)

Schulson EM and Duval P (2009) Creep and fracture of ice. Cambridge University Press, Cambridge

Schweizer J, McCammon I and Jamieson JB (2008) Snowpack observations and fracture concepts for skier-triggering of drysnow slab avalanches. Cold Reg. Sci. Technol., 51(2-3), 112-121 (doi: 10.1016/j.coldregions.2007.04.019)

Theile T, Löwe H, Theile TC and Schneebeli M (2011) Simulating creep of snow based on microstructure and the anisotropic deformation of ice. Acta Mater., 59(18), 7104-7113 (doi: 10.1016/j.actamat.2011.07.065)

Von Moos M, Bartelt P, Zweidler A and Bleiker E (2003) Triaxial tests on snow at low strain rate. Part I. Experimental device. J. Glaciol., 49(164), 81-90 (doi: 10.3189/172756503781830881)

MS received 9 November 2011 and accepted in revised form 31 October 2012 